\title{
Çocuk Hikâye Kitaplarında Spor ve Sağlıklı Yaşam Temasının İncelenmesi*
}

\section{Investigation Of The Theme Of Sports And Healthy Life In Children's Storybooks}

\author{
Mikail Tel a , Yunus Emre Karakaya ${ }^{\text {b }}$ Ercan Gür c,** \\ ${ }^{a}$ Doç. Dr., Frrat Üniversitesi, Sivrice Meslek Yüksekokulu, Otel, Lokanta ve İkram Hizmetleri Bölümü, 23119, Elazığ/Türkiye. \\ ORCID: 0000-0002-0629-7357
}

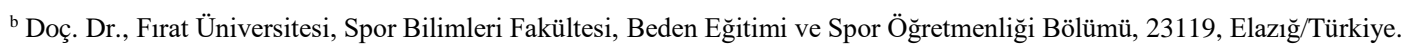
ORCID: 0000-0002-9858-2103

${ }^{c}$ Prof. Dr., Fırat Üniversitesi, Spor Bilimleri Fakültesi, Antrenörlük Eğitimi Bölümü, 23119, Elazı̆̆/Türkiye. ORCID: 0000-0001-6690-828X

\section{MAKALE BİLGISI}

\section{Makale Geçmişi:}

Başvuru tarihi: 04 Temmuz 2020

Düzeltme tarihi: 18 Şubat 2021

Kabul tarihi: 23 Şubat 2021

Anahtar Kelimeler:
Hikâye Kitapları
Spor
Sağlıklı Yaşam

\section{ÖZ}

$\mathrm{Bu}$ araştırma, çocuk hikâye kitaplarında yer alan sağlıklı yaşam ve spor temalarını ortaya koymak amacı ile yapılmıştır. Bu kapsamda, Elazığ İl Halk Kütüphanesi'nde ve ilköğretim okullarında yer alan kütüphanelerde yer alan 100 kitap incelenmiştir. İncelenen eserlerde sağlıklı yaşam teması olarak en yüksek düzeyde, düzenli beslenme, çevre temizliği dinlenme gibi etkinliklere yer verildiği görülmüştür. Kitaplarda, spor teması olarak güreş, kano, basketbol gibi sporlara yer verildiği tespit edilmiştir. Sonuç olarak, çocuklar için hazırlanan kitaplarda spor aktiviteleri ve sağlıklı yaşama yönelik çeşitlilik fazla görülse de sportif aktivitelerini anlatan metinlere düşük düzeyde yer verildiği görülmüştür.

\section{A B S T R A C T}

This study was conducted to reveal the themes of healthy life and sports included in children's storybooks. 100 books, which were included in the Public Town Library and primary schools in the city of Elazı ğ, were examined. In the books that were under investigation, it was observed that activities, such as regular diet, environmental cleaning were included the most as themes of a healthy life. In the books, activities such as wrestling, kayaking, and basketball, were included as themes of sports. In conclusion, although it seemed like the books prepared for children included various sports activities and healty life; it was observed that the texts that covered sports activities and healty life were included in the texts at low levels.

\section{Storybooks}

Sport

Healthy Life

\section{Giriş}

Eğitim, sosyal kalkınma ve ilerlemenin en temel yap1 taşlarındandır. Eğitimde amaç, çocuğun bedenini, zihnini, duygularını eğitmektir. Eğitimin temeli okumaktır. Okuma zihinsel temalar içindeki bir süreçtir. Okumanın en önemli amacı okunan şeylerden anlam ortaya koymaktır (Akyol, 2006). İyi bir okuma yapan bir birey okuduğu şeylerden çeşitli anlamlar öğrenir. Çünkü, kitaplar okuma yeteneklerini geliştirmede sık sık yararlanılan eğitim materyalleridir.

Eğitimin önemli bir parçası olan çocuk kitapları eğitimin vazgeçilmez unsurları arasında sayılmaktadır (Sever, 2002). Çocuk kitapları, çocuklar için vazgeçilmez yol göstericidir. Çocuklar, duygu, düşünce ve davranışlarıyla kendine özgü varlıklardır. Kitaplar, çocukların düşünme ve konuşma

*Bu araştırma, 25-27 Nisan 2018 tarihinde Lviv/Ukraine'de düzenlenen $6^{\text {th }}$ International Conference On Science Culture and Sport'da sunulan "Çocuk Hikâye Kitaplarında Spor ve Sağlıklı Yaşam Temasının İncelenmesi”" başlıklı bildirinin gözden geçirilmiş ve genişletilmiş halidir.

\footnotetext{
** Sorumlu yazar/Corresponding author.

e-posta: emrekarakaya@ firat.edu.tr
} 
becerilerinin gelişmesine katkı sağlamakla birlikte okumayı da heveslendirmektedir. Çocuklar, kitaplarla ne kadar erken tanışırsa yetişkin dünyasına olan uyumu o kadar kolay ve hizlı olacaktır.

Çocuk kitapları, çocukların sosyal, zihinsel, kişilik gelişimi, dil gelişimi gibi konularda gelişmesini sağlar (Bulut ve Kuşdemir, 2013). Kuran (2011)'a göre çocuk hikâye kitapları, içeriğiyle, kurgusuyla, dili ile çocukların beğenilerine ve zevklerine hitap etmektir. Çünkü, kitapların eğlendirme, bilgi verme, eğitim, eğitme gibi amaçları vardır. Çocuk, kitaplar ve kitaplarda bulunan kahramanlar aracılığ ile insan gerçekliğini ve yaşamı tanımaya başlar. Kitaptaki kahramanın/kahramanların özellikleri çocuğun yeni yaşantılar ortaya koymasını sağlamaktadır (Zivtci, 2006). Bulut ve Kuşdemir (2013), çocuk hikâye kitaplarının çocuğa sağladığı faydaları şu şekilde sıralamaktadır:

- Okuma-yazma farkındalığını geliştirme

- İç dünyalarını zenginleştirme

- Yazma ve okuma aktivitelerine kaynak oluşturup okudu şeyleri anlama ve dilin düzgün bir şekilde kullanımını sağlama

- Okuduğu kitapla kendi yaşantıları arasında güçlü bir ilişki kurmasını sağlama

- Kitap okurken zevk alma ve eğlenme firsatı sağlama

- Farklı ve yeni yaşam becerileriyle karşılaşma firsatı verme.

Çocukların çoğu alanlarda gelişimlerine katkı sağlayan kitapların içerikleriyle ilgili faktörler önemlidir. Bunlar, "kitabın temasl, işlenen tema ve konu, kahramanlar, üslup ve dil, plan" olarak siralanabilir (Gönen vd., 2011; Demircan, 2006). Çocukların hayatında büyük bir yere sahip olan çocuk hikâye kitaplarına, gereken titizliğin ortaya konulması gerekmektedir. $\mathrm{Bu}$ sebeple çocuk hikâye kitaplarını ortaya koyacak yazarların, her açıdan çocukların gelişim dönemlerine hâkim olması, onların hangi şeylerden hoşlandıklarını iyi bilmesi, yazarın dilinin sade ve akıcı olması ve ana fikri kendi içinde doğal bir anlatım tarzıyla vermesi önem arz etmektedir (Dağlığlu ve Çakmak, 2009; Tekin, 2005; Ataseven ve İnand1, 2000). Çocuklar kitaplar içerisinde geçen karakterlerle bir özdeşim kurarak onlar gibi olma ve onlar gibi davranma davranışı göstermektedirler. Bazı değerlerin öğrencilerde yerleşmesi için kitaplar önem arz etmektedir. Bunlardan biri de sağlıklı yaşam ve spor aktiviteleridir. Spor, bir yaşam tarzıdır (Filiz, 2002). Spor faaliyetleri, insanların yaşamlarında son derece önemli bir sosyal etkinlik olarak kabul edilmektedir. Spor, insan sağlığının daha verimli bir ortamda devam etmesi için yapılması gereken fiziksel aktivitelerdir. Sağlıklı yaşama ulaşmak için spor bir araçtır.

Sağlıklı yaşam aktiviteleri, herhangi bir kronik rahatsızlığı önlemeye yönelik olmayıp, bireyin sağlık durumunu daha da iyileştirmeyi amaçlamaktadır (Edelman ve Mandle, 1986). Günümüzde, çoğu sağlık problemlerinin sağlığa ilişkin davranışların, tutumların olmayışı ve hareketli olmayan bir yaşamdan kaynaklandığı ifade edilmektedir (Redland ve Stuifbergen, 1993; Pender, 1987). Yapılan araştırmalarda, hareketli olmayan bir yaşam tarzının insanlarda çeşitli kronik hastalıklara neden olduğu belirtilmektedir (Arslan ve Ceviz, 2007; Costanzo vd., 2006; Lees ve Booth, 2005). Ayrica, vücut kompozisyonun ve genel sağlığın korunmasında yeterli ve dengeli beslenme ve ayrıca düzenli bir egzersize de ihtiyaç vardır (Arslan ve Ceviz, 2007). Sağlıklı yaşamda temel amaç, her yönüyle daha sağlıklı ve uzun bir yaşam sürebilmektir (Zorba, 2012). Dünya Sağl1k Örgütü'nün tanımına göre "săglık, yalnızca hastalık veya sakatlı̆̆ın olmaması değil, fiziksel, ruhsal ve sosyal olarak tam bir iyilik halidir" (WHO, 2006). Sağlıklı yaşam biçimi, sağlık davranışlarının sorumluluğunu alma, yeterli ve düzenli egzersiz yapma, dengeli beslenme, sigara kullanmama, kişisel temizlik, sağlık sorumluluğu, kişiler arası olumlu ilişkiler kurmadır (Özvarış, 2006). Sağlıklı yaşam biçimi aktivitelerini yaşamın bir parçası olarak ortaya koyan bir birey, sağlıklı olmayı sürdürebildiği gibi, sağlık durumunu da daha güzel bir hale dönüştürebilir (Zaybak ve Fadıloğlu, 2004). Hareketsiz bir yaşam sonucunda vücudumuzda, kas ve iskelet sisteminde, kan değerlerinde, dolaşım sisteminde, sindirim ve solunum sisteminde, stres ve psiko- sosyal fonksiyonlarda bazı sıkıntılar görülmektedir (Zorba, 2012; Erkan, 1998). Bunlardan korunmanın ve sağlığ tek ve en etkin yolu egzersiz yaparak sağlığa kavuşmaktır. Sağlık davranışı, bireyin sağlıklı kalması ve hastalıklardan korunması için inandığı ve uyguladığı davranışların bütün halidir. Düzenli bir egzersizin sağlıklı bir yaşam üzerinde olumlu etkisi vardır.

$\mathrm{Bu}$ genel bilgilerden yola çıkarak eğitimin vazgeçilmez unsuru olan kitaplar sağlıklı yaşam ve spor alışkanlığı edinmede kuşkusuz önemli bir yere sahiptir. Çocuğun hikâye kitaplarında geçen karakterleri, onların güzel davranışlarını örnek alarak kendi hayatına taşıma imkânına sahiptir. Kitaplar sayesinde çocuklar, karakterlerin davranışlarını ve yaptıklarını kendine örnek alarak bir takım alışkanlıkları kolaylıkla benimseyebilir. Yapılan literatür incelendiğinde, çocuklar için hazırlanan hikâye kitaplarının içeriğine yönelik yapılan araştırmalar oldukça kısıtlıdır. Sağlıklı yaşam isteği ve spor yapmak her yaş dönemindeki bireyin önemsediği ve devamını istediği bir konudur. Bunun bilinçli bir hale dönüşmesi ise çocukken başlayarak devam ettirilmesi ve sevdirilmesiyle mümkündür. Çocuklara sağlıklı yaşam ve spor kültürü özümsetmek önemlidir. Sağlıklı yaşam ve spor etkinlikleri açısından çocuk hikâye kitaplarında bu konunun işlenmesi ve bu alışkanlığın kazandırılması önem taşımaktadır. $\mathrm{Bu}$ kapsamda yapılan araştırmada, çocuk hikâye kitaplarında metin içerisinde geçen sağlıklı yaşam ve spor etkinliklerinin hangi düzeyde ve sıklıkla verildiği belirlenmeye çalışılmıştır.

\section{Yöntem}

$\mathrm{Bu}$ araştırma, survey modeli kullanılarak yapılmıştır. $\mathrm{Bu}$ model, var olan bir durumu aynı şekilde ortaya koymayı (Yıldırım ve Şimşek, 2005; Karasar, 1995) amaçlamaktadır. Geçmişte veya halen var olan bir durumu betimleyen bir araştırma modelidir. Ayrıca bu araştırma sürecinin güvenirliği açısından, "uzman incelemesi" stratejisi benimsenmiştir (Dağlığlu ve Çakmak, 2009; Yıldırım ve Şimşek, 2005). Bu kapsamda, çocuk hikâye kitaplarında sağlıklı yaşam ve spor temalarını alan metinleri değerlendirmek amaçlanmıştır.

Araştırmada, Elazığ İl Halk Kütüphanesi'nde ve bazı ilköğretim okullarındaki kütüphanelerde yer alan çocuk hikâye kitapları taranmıştır. Bu hikâye kitaplarının 89'u ulusal, 11'i yabancı yazarlar tarafından kaleme alınmıştır. 
Araştırma kapsamında rastgele yöntemle seçilmiş yayınevlerinin yayınlanmış 100 hikâye kitabının içeriğinde geçen metinlerde "sağlıklı yaşam ve spor" açısından incelenmesi, araştırmacılar tarafindan bir "değerlendirme formu” ile elde edilmiştir. Bu form, üç bölümden oluşmakta olup, ilk bölümde kitabın adı, yazarı, yılı, yayınevi, sayfası gibi özellikleri, ikinci bölümde metinlerde sağlıklı yaşam ve üçüncü bölümde metinlerde spor öğelerini sorgulayan maddeler yer almıştır. Ayrıca, değerlendirme formunda hangi aktivitenin kaç defa yapıldığından çok, hangi sağlıklı yaşam aktivitelerinin ve hangi spor branşlarının yapıldığı değerlendirilmiştir.

Araştırmada, hikâye kitaplarının "sağlıklı yaşam ve spor" temaları açısından ortaya konulması için birincil ve ikincil kaynaklara ulaşılmaya çalışılmıştır. Araştırma kapsamında inceleme sonucunda bu hikâye kitaplarındaki "sağlıklı yaşam ve spor" temalarının ortaya konulmasına yönelik olarak bir resmi ölçütünde olmadığı görülmüştür.

\section{Bulgular}

$\mathrm{Bu}$ bölümde ilköğretim seviyesindeki çocuklara yönelik olarak hazırlanmış hikâye kitaplarının içeriğinde sağlıklı yaşam ve sporla alakalı olan temalar verilmiştir.

Tablo 1' e göre sağlıklı yaşamın taranan eserler içerisinde 54'ünde görülmemiştir. Kalan 46 kitap içeriğinde ise farklı düzeylerde ve sayılarda sağlıklı yaşam aktivitelerinin olduğu tespit edilmiştir. Spor teması olarak kitap içeriklerinde 68 kitapta oyun temasını içeren aktiviteler görülmemişken, 32 kitap içeriğinde ise çeşitli seviyelerde ve sayılarda spor aktiviteleri belirlenmiştir.

Tablo 1. Hikâye Kitaplarının Kitap Adı, Yazar, Yıl, Yayınevi, Sayfa, Sağlıkı Yaşam ve Spor Temalarına Yönelik Analiz

\begin{tabular}{|c|c|c|c|c|c|c|c|}
\hline No & Kitap Adı & Yazar & Yil & Yayınevi & Sayfa & $\begin{array}{l}\text { Sağlıklı } \\
\text { Yaşam }\end{array}$ & Spor \\
\hline 1 & Yolcu ile Ayı & $\begin{array}{l}\text { Ekrem Batur } \\
\text { Musanoğlu }\end{array}$ & 2006 & Kök & 18 & - & $\begin{array}{c}\text { Vücut } \\
\text { Geliştirme, } \\
\text { Yürüme } \\
\end{array}$ \\
\hline 2 & $\begin{array}{c}\text { Bilgin Amca ve Uçan } \\
\text { Balon }\end{array}$ & Öykü Zeren & 2010 & Polat & 16 & - & Yürüme \\
\hline 3 & Selimin Mavi İncisi & Hikmet Ulusoy & 2011 & $\begin{array}{c}\text { Çilek } \\
\text { Kitapları }\end{array}$ & 22 & $\begin{array}{l}\text { Spor, } \\
\text { Oyun }\end{array}$ & $\begin{array}{l}\text { Yüzmek, } \\
\text { Dalgıçlık }\end{array}$ \\
\hline 4 & İyilik Yap Denize At & Mehmet Teber & 2008 & $\begin{array}{l}\text { Hepsi } \\
\text { Çocuk }\end{array}$ & 10 & $\begin{array}{l}\text { Balık Yemek, } \\
\text { İlaç kullanmak }\end{array}$ & $\begin{array}{c}\text { Kampçılık, } \\
\text { Balık Tutmak }\end{array}$ \\
\hline 5 & Palyaço Okulu & Mavisel Yener & 2013 & $\begin{array}{c}\text { Bilgi } \\
\text { Yayınevi }\end{array}$ & 23 & - & - \\
\hline 6 & Vefalı At & $\begin{array}{c}\text { Sara Gürbüz } \\
\text { Özeren }\end{array}$ & 2012 & Damla & 48 & - & $\begin{array}{c}\text { Güreş, } \\
\text { At Binme }\end{array}$ \\
\hline 7 & Şarkılı Bahçe & Münevver Oğan & 2011 & $\begin{array}{l}\text { Yeni } \\
\text { Umut }\end{array}$ & 20 & $\begin{array}{c}\text { Temizlik } \\
\text { alışkanlığ1 }\end{array}$ & - \\
\hline 8 & Kimsecikler Yok Mu? & Yaprak Meral & 2011 & Can Sanat & 33 & - & - \\
\hline 9 & Güneş ile Kovalamaca & Arife Gülemen & 2005 & Yeni Asya & 48 & $\begin{array}{c}\text { Dinlenme, } \\
\text { Düzenli Uyku }\end{array}$ & - \\
\hline 10 & Sevimli Balık Yunus & Nurdan Damla & 2010 & $\begin{array}{l}\text { Nesil } \\
\text { Çocuk } \\
\end{array}$ & 16 & $\begin{array}{c}\text { Vücut } \\
\text { Temizliği } \\
\end{array}$ & - \\
\hline 11 & Uzaydan Gelenler & Sara Gürbüz & 2012 & Damla & 48 & - & - \\
\hline 12 & Dinazor Teri & Nefise Atçakarlar & 2011 & Timaş & 24 & - & Koşu Yapma \\
\hline 13 & Fareli Köyün Kavalcısı & Anomin & 2005 & Yakamoz & 10 & - & - \\
\hline 14 & $\begin{array}{c}\text { Doğum Günün Kutlu } \\
\text { Olsun } \\
\end{array}$ & Sevda Yüksel & 2016 & Yuva & 64 & - & Balık Avlamak \\
\hline 15 & Toprak ve Yağmur & Melike Tamsoy & 2016 & Yuva & 64 & - & - \\
\hline 16 & S1k1ld1m & Olcay Güner & 2015 & Elif & 24 & - & Yüzmek \\
\hline 17 & Masal Güzel İsimler & İzzet Oral & 2016 & Yuva & 64 & - & $\begin{array}{c}\text { Yüzme, } \\
\text { Kano }\end{array}$ \\
\hline 18 & Yaban Kuyuları & $\begin{array}{c}\text { Hüseyin } \\
\text { Demirkapı }\end{array}$ & 2008 & Zambak & 40 & $\begin{array}{c}\text { Vücut } \\
\text { temizliği }\end{array}$ & - \\
\hline 19 & $\begin{array}{c}\text { Özür Dilemeli Nasıl } \\
\text { Dilemeli }\end{array}$ & İffel Oval & 2016 & Yuva & 64 & - & - \\
\hline 20 & Hobi Bahçesi & Nazan Özen & 2016 & $\begin{array}{c}\text { Yuva } \\
\text { Yayınevi }\end{array}$ & 64 & $\begin{array}{l}\text { Diş Bakımı, } \\
\text { Diyet }\end{array}$ & - \\
\hline 21 & Aslanın Sirrı & $\begin{array}{c}\text { Demirhan } \\
\text { Kadıŏlu } \\
\end{array}$ & 2008 & $\begin{array}{l}\text { Hepsi } \\
\text { Çocuk } \\
\end{array}$ & 10 & - & $\begin{array}{c}\text { Dağ Tirmanışı, } \\
\text { Yüzme }\end{array}$ \\
\hline 22 & Tavus Kuşu & Mehmet Teber & 2008 & $\begin{array}{l}\text { Hepsi } \\
\text { Çocuk }\end{array}$ & 10 & - & $\begin{array}{c}\text { Trekking, } \\
\text { At Biniciliği } \\
\end{array}$ \\
\hline 23 & Evladın Böylesi & Mehmet Teber & 2008 & $\begin{array}{l}\text { Hepsi } \\
\text { Çocuk }\end{array}$ & 6 & - & At Biniciliği \\
\hline
\end{tabular}


Tel, M., Karakaya, Y.E. \&. Gür, E. / Anemon Muş Alparslan Üniversitesi Sosyal Bilimler Dergisi, 2021 9(2) 509-517 512

\begin{tabular}{|c|c|c|c|c|c|c|c|}
\hline 24 & Dilencinin Rüyası & Mehmet Teber & 2008 & $\begin{array}{l}\text { Hepsi } \\
\text { Çocuk }\end{array}$ & 6 & $\begin{array}{c}\text { Sağlıklı } \\
\text { Beslenme }\end{array}$ & - \\
\hline 25 & Konuk At & Abdurrahman Kas & 2015 & Akvaryum & 16 & - & At Binmek \\
\hline 26 & $\begin{array}{c}\text { Sürüden Ayrılan } \\
\text { Kuzucuk }\end{array}$ & Müzeyyen Özgül & 2017 & Yuva & 16 & - & - \\
\hline 27 & Tilki İle Tavşan & Orhun Buğrahan & 2010 & Zambak & 56 & - & - \\
\hline 28 & Futbol Masalı & Öznur Kalındır & 2010 & Coşkun & 12 & - & Futbol \\
\hline 29 & Sporcu Fil Bobo & Öznur Kalındır & 2010 & Coşkun & 12 & - & - \\
\hline 30 & Kartal ile Baykuş & $\begin{array}{c}\text { Jean De } \\
\text { Lafontaine }\end{array}$ & 2010 & Gönül & 16 & - & - \\
\hline 31 & Hayvanlar İş Başında & Öznur Kalındır & 2010 & Coşkun & 12 & - & - \\
\hline 32 & Dut Yemiş Bülbül & Yakup Kavaş & 2008 & Zambak & 56 & - & Okçuluk \\
\hline 33 & Dans Eden Balıklar & Ülkü Duysak & 2016 & Yuva & 64 & $\begin{array}{c}\text { Çevre } \\
\text { Temizliği }\end{array}$ & - \\
\hline 34 & Çoban ile Kral & $\begin{array}{l}\text { Mahmut Orhan } \\
\text { Buğrahan }\end{array}$ & 2008 & Zambak & 56 & Beslenme & Ava Çıkmak \\
\hline 35 & Periler Diyarı & Melike Tansoy & 2008 & Yuva & 48 & $\begin{array}{c}\text { Diş Temizliği, } \\
\text { Yıkanma } \\
\text { Alışkanlığ }\end{array}$ & - \\
\hline 37 & $\begin{array}{l}\text { Baba Penguenin } \\
\text { Fedakarlığ } 1\end{array}$ & $\begin{array}{l}\text { Sara Gürbüz } \\
\text { Özeren }\end{array}$ & 2012 & Damla & 48 & $\begin{array}{c}\text { Düzenli } \\
\text { Beslenme, } \\
\text { Uyku Düzeni }\end{array}$ & Atletizm \\
\hline 38 & Tuhaf Kaplan & Kemal Seyit & 2012 & Nar & 17 & - & - \\
\hline 39 & $\begin{array}{l}\text { Aburlup Cuburlup } \\
\text { Tumburluplar }\end{array}$ & Meltem Erinçmen & 2013 & Çikolata & 16 & $\begin{array}{c}\text { Düzenli } \\
\text { Beslenme ve } \\
\text { Önemi } \\
\end{array}$ & Atletizm \\
\hline 40 & Korsan & Feride İlgün & 2015 & Ferfir & 48 & Hareket Etme & - \\
\hline 41 & Küçük Kirlangıç & Turgay Arıçıoğlu & 2009 & Ünlü & 16 & - & - \\
\hline 42 & Kiralık Canavar & $\begin{array}{c}\text { Andreas } \\
\text { Steinhöfel }\end{array}$ & 2015 & Tudem & 104 & - & - \\
\hline 43 & $\begin{array}{c}\text { Al Takkeli Dev ile Mor } \\
\text { Takkeli Dev }\end{array}$ & Ayla Çınaroğlu & 1996 & $\begin{array}{l}\text { Uçan } \\
\text { Balık }\end{array}$ & 32 & $\begin{array}{c}\text { Düzenli } \\
\text { Beslenme }\end{array}$ & - \\
\hline 44 & Çınarın Feryadı & $\begin{array}{l}\text { Sana Gürbüz } \\
\text { Özeren }\end{array}$ & 2012 & Damla & 44 & - & At Binmek \\
\hline 45 & Altın Kanatlı Top Çin & Ayla Çınaroğlu & 2009 & $\begin{array}{l}\text { Uçan } \\
\text { Balık }\end{array}$ & 80 & - & - \\
\hline 46 & Berber Masalı & Ayla Çınaroğlu & 2008 & $\begin{array}{l}\text { Uçan } \\
\text { Balık } \\
\end{array}$ & 32 & $\begin{array}{c}\text { Temizlik } \\
\text { Alışkanlığı }\end{array}$ & - \\
\hline 47 & Atatürk Olmak & Aytül Akal & 2012 & $\begin{array}{l}\text { Uçan } \\
\text { Balık }\end{array}$ & 24 & - & - \\
\hline 48 & Açgözlü Kurt & $\begin{array}{c}\text { Sara Gürbüz } \\
\text { Özveren }\end{array}$ & 2012 & Damla & 48 & $\begin{array}{c}\text { Sağliklı } \\
\text { Beslenme } \\
\end{array}$ & - \\
\hline 49 & Ellerimdeki Kelimeler & $\begin{array}{l}\text { Benedicte } \\
\text { Gourdon }\end{array}$ & 2012 & Desen & 32 & - & - \\
\hline 50 & $\begin{array}{c}\text { Duygunun Doğum Günü } \\
\text { Armağanı }\end{array}$ & Betül Avunç & 2008 & Kültür & 72 & - & - \\
\hline 51 & Denize Düşen Denizkızı & Çiğdem Gündeş & 2008 & Tudem & 48 & - & Yüzme \\
\hline 52 & Obur Prenses & Çiğdem Gündeş & 2008 & Tudem & 36 & $\begin{array}{l}\text { Sağlıksız } \\
\text { Beslenme } \\
\end{array}$ & - \\
\hline 53 & $\begin{array}{l}\text { Bilmecenin İzinde } \\
\text { Maceranın Peşinde }\end{array}$ & $\begin{array}{c}\text { Dursun Ege } \\
\text { Göçmen }\end{array}$ & 2011 & Tudem & 120 & - & - \\
\hline 54 & Ben Kırmadım & $\begin{array}{l}\text { Sara Gürbüz } \\
\text { Özeren }\end{array}$ & 2012 & Damla & 47 & $\begin{array}{c}\text { Düzenli } \\
\text { Beslenme }\end{array}$ & $\begin{array}{l}\text { Yürüme } \\
\text { Koşmak }\end{array}$ \\
\hline 55 & Bisiklet Yarışçıları & $\begin{array}{c}\text { Ferda İzbudak } \\
\text { Akıncı }\end{array}$ & 2014 & Tudem & 160 & - & Bisiklet \\
\hline 56 & Küçük Ressam & $\begin{array}{l}\text { Hamdullah } \\
\text { Köseoğlu }\end{array}$ & 2011 & Özyürek & 48 & - & - \\
\hline 57 & Büyük Annem Cebimde & İva Frochazkova & 2017 & Tudem & 160 & - & - \\
\hline 58 & Bayan Pimpirik & İclal Dikici & 2014 & Kök & 110 & $\begin{array}{c}\text { Temizlik } \\
\text { Alışkanlığı }\end{array}$ & - \\
\hline
\end{tabular}




\begin{tabular}{|c|c|c|c|c|c|c|c|}
\hline 59 & Maskeli Kıraça & $\begin{array}{l}\text { Fidan Çobanoğlu } \\
\text { Kaplan }\end{array}$ & 2010 & Top & 54 & $\begin{array}{c}\text { Düzenli } \\
\text { Beslenme, } \\
\text { Temizlik } \\
\text { Alışkanlığ1 } \\
\end{array}$ & - \\
\hline 60 & Buzdan Köprüler Eridi & Gülnar Kandeyer & 2012 & Berkay & 48 & Düzenli Uyku & - \\
\hline 61 & Kuş Yuvası & Leyla Fidanay & 2009 & Ata & 57 & - & Futbol \\
\hline 62 & $\begin{array}{l}\text { Deniz Yıldızı Kayası } \\
\text { Arkadaşım Balina }\end{array}$ & Kelly Mckain & 2012 & Kültür & 48 & - & - \\
\hline 63 & Ahmethan'ın Rüyası & Arife Kalender & 2014 & Neziher & 40 & $\begin{array}{c}\text { Çevre } \\
\text { Temizliği } \\
\end{array}$ & - \\
\hline 64 & Pitırcık ile Mizmız & Anomin & 2004 & Ata & 32 & Düzenli Uyku & - \\
\hline 65 & S1k1 Dostlar & $\begin{array}{l}\text { Emine Yalçın } \\
\text { Tuğrul } \\
\end{array}$ & 2004 & Ata & 60 & - & - \\
\hline 66 & Hayat Ağacı & $\begin{array}{l}\text { Sara Gürbüz } \\
\text { Özeren }\end{array}$ & 2012 & Damla & 47 & $\begin{array}{l}\text { Kişisel Bakım, } \\
\text { Temizlik }\end{array}$ & - \\
\hline 67 & Kralın Yeni Giysileri & Selver Sağlam & 2008 & Berkay & 64 & - & - \\
\hline 68 & $\begin{array}{l}\text { Kirli Mikrop ile Zararlı } \\
\text { Mikrop } \\
\end{array}$ & Adnan Özveri & 2008 & Phoenix & 48 & Diş Temizliği & - \\
\hline 69 & Korkunç Gölge & Mavisel Yener & 2011 & Tudem & 31 & - & - \\
\hline 70 & Nene Hatun & $\begin{array}{l}\text { Sara Gürbüz } \\
\text { Özeren }\end{array}$ & 2012 & Damla & 48 & Düzeni uyku & Yürüme \\
\hline 71 & Ev Korsanı & Nurgül Ateş & 2011 & $\begin{array}{l}\text { Çizmeli } \\
\text { Kedi }\end{array}$ & 48 & - & - \\
\hline 72 & Karadaylak & Afet Ilgaz & 2006 & Salıncak & 48 & - & - \\
\hline 73 & $\begin{array}{c}\text { Kahraman Kedi Zıp Zıp } \\
\text { Pirelere Karşı }\end{array}$ & Alberto Pez & 1997 & $\begin{array}{l}\text { Marsik } \\
\text { Kitap }\end{array}$ & 16 & $\begin{array}{l}\text { Düzensiz } \\
\text { Uyku, } \\
\text { Vücut } \\
\text { Temizliği }\end{array}$ & - \\
\hline 74 & İp Bacaklı Uzaylı Çocuk & Aytül Akar & 1997 & $\begin{array}{l}\text { Uçan } \\
\text { Balık }\end{array}$ & 16 & $\begin{array}{l}\text { Düzensiz } \\
\text { Beslenme }\end{array}$ & - \\
\hline 75 & Güneşin Öfkesi & $\begin{array}{l}\text { Sara Gürbüz } \\
\text { Özeren }\end{array}$ & 2012 & Damla & 48 & - & Yürüme \\
\hline 76 & Kemanc1 Ayı Masalı & Fatih Erdoğan & 2007 & $\begin{array}{l}\text { Mavi } \\
\text { Bulut }\end{array}$ & 63 & - & Yüzme \\
\hline 77 & Eğlenceli Alışveriş & Ayşen Oy & 2004 & Epsilon & 16 & - & Yürüme \\
\hline 78 & Tembel Kedi Jose & $\begin{array}{c}\text { Fransziska } \\
\text { Biermann } \\
\end{array}$ & 2017 & Hep Kitap & 36 & - & - \\
\hline 79 & Yavru Fino & Rafet Sutuğlu & 2010 & Çalışkan & 48 & Diş Temizliği & Kayak \\
\hline 80 & Ananemin Kedileri & Sevda Yüktel & 2008 & Yuva & 64 & & Bisiklet Sürme \\
\hline 81 & Ferfene & Rafet Sutuğlu & 2008 & $\begin{array}{c}\text { Çalışkan } \\
\text { Arı }\end{array}$ & 48 & $\begin{array}{c}\text { Çevre } \\
\text { Temizliği }\end{array}$ & - \\
\hline 82 & Hayal & Melike Tansoy & 2008 & Yuva & 63 & - & Yüzme \\
\hline 83 & Su Bebekleri & Charles Kingsley & 2010 & Sıradışı & 48 & - & - \\
\hline 84 & Derebahçe Köyü & Rafet Sutuğlu & 2008 & Murat & 48 & - & - \\
\hline 85 & Bilim Sanatlı Haz & Rafet Sutuğlu & 2008 & Murat & 48 & Sporun Önemi & - \\
\hline 86 & Canım Hırkacım & Nazan Özan & 2010 & Yuva & 64 & - & Futbol \\
\hline 87 & Kaval Çalan Balıkçı & Orhan Buğrahan & 2008 & Zambak & 56 & - & - \\
\hline 88 & Bencil Devin Bahçesi & Ali Olgar & 2014 & Gönül & 64 & - & Dans Etmek \\
\hline 89 & Sinbad'ın Maceraları & Mustafa Doğru & 2016 & Yumurcak & 16 & - & - \\
\hline 90 & $\begin{array}{c}\text { Cemile Sağlıklı } \\
\text { Yaşamayı Öğreniyor }\end{array}$ & Yasmin Bradley & 2014 & $\begin{array}{l}\text { Kaknüs } \\
\text { Çocuk }\end{array}$ & 14 & $\begin{array}{c}\text { Beslenme, } \\
\text { Sporun Önemi }\end{array}$ & - \\
\hline 91 & Heidi & Johanna Spyri & 2017 & İskek & 120 & Beslenme & - \\
\hline 92 & Küçük Kemancı & $\begin{array}{l}\text { Eleanore H. } \\
\text { Partem }\end{array}$ & 2017 & Özyürek & 72 & - & - \\
\hline 93 & Robin Hood & Howard Pyle & 2017 & İskek & 80 & - & $\begin{array}{l}\text { Okçuluk, } \\
\text { Yürüme }\end{array}$ \\
\hline 94 & $\begin{array}{l}\text { Dağınık Emre'nin } \\
\text { Rüyası }\end{array}$ & $\begin{array}{l}\text { Sara Gürbüz } \\
\text { Özeren }\end{array}$ & 2012 & Damla & 48 & $\begin{array}{c}\text { Temizlik } \\
\text { Alışkanlığı, } \\
\text { Çevre } \\
\text { Temizliği } \\
\end{array}$ & Futbol, Atletizm \\
\hline
\end{tabular}


Tel, M., Karakaya, Y.E. \&. Gür, E. / Anemon Muş Alparslan Üniversitesi Sosyal Bilimler Dergisi, 2021 9(2) 509-517 514

\begin{tabular}{cccccccc}
\hline $\mathbf{9 5}$ & Çılgın Palyaço ile Çişil & Devrim Altay & 2012 & Ata & 32 & $\begin{array}{c}\text { Sağlıklı } \\
\text { Beslenme }\end{array}$ & - \\
\hline $\mathbf{9 6}$ & Yolculuk & Önder Karçığa & 2011 & Morpa & 32 & $\begin{array}{c}\text { Çevre } \\
\text { Temizliği }\end{array}$ & - \\
\hline $\mathbf{9 7}$ & $\begin{array}{c}\text { Yuvasız Kalan } \\
\text { Hayvanlar }\end{array}$ & Devrim Altay & 2010 & Ata & 32 & - & $\begin{array}{c}\text { Yüzme, } \\
\text { Koşmak, } \\
\text { Yürüme }\end{array}$ \\
\hline $\mathbf{9 8}$ & Deniz Yaz Kampında & Aydoğan Yavaşlı & 2012 & Bulut & 32 & $\begin{array}{c}\text { Sağlıklı } \\
\text { Beslenme }\end{array}$ & $\begin{array}{c}\text { Yüzme, } \\
\text { Su Topu, } \\
\text { Basketbol }\end{array}$ \\
\hline $\mathbf{9 9}$ & Mızmız Arı & Hülya Serbest & 2007 & $\begin{array}{c}\text { Şule } \\
\text { Çocuk }\end{array}$ & 16 & $\begin{array}{c}\text { Sağlıklı } \\
\text { Beslenme }\end{array}$ & - \\
\hline $\mathbf{1 0 0}$ & Harf Küpleri & Gülnar Kandeyer & 2010 & Berkay & 16 & - & - \\
\hline
\end{tabular}

Tablo 2. Hikâye Kitaplarının İçerisinde Geçen Sağlıklı Yaşam Aktivitelerinin Dağı̆lımı

\begin{tabular}{cc}
\hline Aktiviteler & Aktivite Sayısı \\
\hline Düzenli Beslenme & 15 \\
\hline Çevre Temizliği & 11 \\
\hline Düzenli Uyku & 7 \\
\hline Diş Temizliği- Firçalama & 4 \\
\hline Diyet & 3 \\
\hline Spor Yapma Önemi & 3 \\
\hline Dinlenmek & 1 \\
\hline Yikanma Alışkanlı̆̆ı & 1 \\
\hline İlaç Kullanmak & 1 \\
\hline Oyun & 1 \\
\hline
\end{tabular}

Araştırma kapsamında çocuk hikâye kitaplarının içerikleri incelendiğinde, sağlıklı yaşam olarak belirlenen aktiviteler Tablo 2' de verilmiştir. "Düzenli beslenme” kapsamında incelenen eserler içerisinde çocuklara verilmek istenen ve sıklıkla yapılan bir aktivite olarak görülmüştür. Bu aktivite, 15 kitabın içeriğinde kullanılmıştır. "Çevre temizliği kapsamında incelenen eserler içerisinde çocuklara verilmek istenen ve sıklıkla yapılan bir aktivite olarak tespit edilmiştir.
Bu aktivite, 11 kitabın içeriğinde kullanılmıştır. "Düzenli uyku", kitaplar içerisinde incelendiğinde, aktivite 7 kitabın içeriğinde kullanılmıştır. "Diş firçalama ve temizliği" incelenen eserlerde, 4 kitap içerisinde kullanılmıştır. "Diyet, ve "Spor yapmanın önemi" kitaplar içerisinde 3 kitap içerisinde kullanılmıştır. "Dinlenmek”, "Ylkanma alışkanlığl, "İlaç kullanmak ve oyun" kitaplar içerisinde 1 kitap içerisinde kullanılmıştır.

Tablo 3. Hikâye Kitaplarının İçerisinde Geçen Spor Aktivitelerinin Dağılımı

\begin{tabular}{cl}
\hline Aktiviteler & Aktivite Sayıs \\
\hline Yüzme & 8 \\
\hline Yürüme & 8 \\
\hline At Binme & 5 \\
\hline Atletizm-Koşu & 6 \\
\hline Futbol & 4 \\
\hline Treaking-Yürüyüş & 2 \\
\hline Ava Gitme & 2 \\
\hline Okçuluk & 2 \\
\hline Bisiklet & 2 \\
\hline Balı Tutma & 1 \\
\hline Güreş & 1 \\
\hline Kano & 1 \\
\hline Dăg Tirmanış1 & 1 \\
\hline Vücut Geliştirme & 1 \\
\hline Kampç1lk & 1 \\
\hline Kayak & 1 \\
\hline Dans Etme & 1 \\
\hline Su Topu & 1 \\
\hline Basketbol & 1 \\
\hline
\end{tabular}


İncelenen çocuk hikâye kitaplarında spor olarak belirlenen aktivitelerin dağılımı Tablo 3'de verilmiştir. "Yüzme" ve "Yürüme" kitaplar içerisinde çocuklara verilmek istenen ve s1klıkla yapılan bir aktivite olarak belirlenmiştir. Bu aktivite 8 kitap içerisinde kullanılmıştır. "At binme” kitap içerisinde, çocuklara verilmek istenen ve sıklıkla yapılan bir aktivite olarak tespit edilmiştir. Bu aktivite 5 kitapta farklı sayılarda metin içerisinde kullanılmıştır. "Futbol" kitap içerisinde, çocuklara verilmek istenen ve sıklıkla yapılan bir aktivite olarak görülmektedir. Bu aktivite 4 kitapta farklı sayılarda metin içerisinde kullanılmıştır. "Atletizm-Koşu” kitap içerisinde, 6 kitapta farklı yerlerde metin içerisinde kullanılmıştır. "Trekking-Yürüyüşs", "Ava Gitme”, "Okçuluk”, "Bisiklet” kitaplar içerisinde, 2 kitap içerisinde kullanılmıştır. "Balık Tutma”, "Güreş", "Kano”, "Dağ Tirmanışı”, "Vücut Geliştirme”, "Kampçılık”, "Kayak”, "Dans Etme”, "Su Topu” ve "Basketbol” incelenen kitaplar içerisinde 1 kitap içerisinde kullanılmıştır.

\section{Sonuç ve Öneriler}

Çocuk hikâye kitapları çocukların eğitim sürecinde vazgeçilmez bir olgu olarak kullanılmaktadır. Bunun için çocukların gelişim özellikleri, yaşları, ihtiyaçları ve ilgileri göz önünde bulundurularak hazırlanmış özgün kitapların ortaya konulması önem taşımaktadır. Yapılan araştırmalarda, çocukların okudukları eğitim kitaplarının dışında en fazla hikâye kitapları okudukları tespit edilmiştir (Öztürk ve Can, 2013). Gönen vd. (2004) yaptığ1 araştırmada, her sosyo-ekonomik seviyedeki öğrencilerin en çok roman ve hikâye türünü tercih ettikleri ve erkeklerin çizgi romanı kızlardan daha çok okuduklarını tespit etmişlerdir.

Yapılan bu araştırmada çocuk hikâye kitapları sağlıklı yaşam ve spor aktiviteleri açısından incelenmiştir. Yayınlanmış olan 100 hikâye kitabının incelenmesi neticesinde aşağıdaki sonuçlara ulaşılmıştır: İncelenen kitaplarda, sağlıklı yaşam teması olarak en yüksek düzeyde düzenli beslenme, çevre temizliği, düzenli uyku, diş temizliği- fırçalama, diyet, spor yapma önemi, dinlenmek, yıkanma alışkanlığı, ilaç kullanma, oyun gibi etkinliklere yer verildiği belirlenmiştir. Çocuklar için hazırlanan kitaplarda sağlıklı yaşamı destekleyici aktivitelere düşük seviyelerde yer verildiği belirlenmiştir. Çocukların sağlıklı yaşam alışkanlığı edinmesinde çocuk kitaplarında verilecek bu aktivitelerin önemi büyük önem taşımaktadır. İncelenen eserlerde spor teması olarak da yüzme, yürüme, koşmak, at binme, futbol, atletizm-koşu, trekking-yürüyüş, ava gitme, okçuluk, bisiklet, balık tutma, güreş, kano, dağ tırmanışı, vücut geliştirme, kampçılık, kayak, dans etme, su topu, basketbol gibi sporlara yer verildiği belirlenmiştir. Kitaplarda spor aktivitesi olarak ele alınacak aktivitelerde çeşitlilik daha fazla belirlenmiştir. Sportif aktivitelerini anlatan metinlere düşük oranlarda yer verildiği görülmüştür. Sonuç olarak, çocuk hikâye kitaplarında spor teması olarak yüzme, at binme, futbol, koşu aktivitelerine yer verilmiş, ancak genel olarak düşük seviyede yer verilmiştir. Sağlıklı yaşam teması olarak düzenli beslenme, vücut ve çevre temizliği, yürüyüş gibi daha yüksek seviyede metin içerisinde yer verildiği belirlenmiştir. Araştırmadan elde edilen sonuçlara yönelik şu öneriler sunulabilir:

- Çocuk hikâye kitaplarında sağlıklı yaşam ve spor alışkanlığının verilmesi önemli olmakla birlikte ailelerde, medyada bu tür bilgilerin sunulması destekleyici olacaktır.

- Çocuk hikâye kitapları içerisinde geçen metinlerde sağlıklı yaşam aktiviteleri ve spor branşları açısından zenginleştirilmesi gerekmektedir.

- Çocuk hikâye kitapları okul ve sınıf kitaplıklarında daha çok yer alması sağlanmalıdır.

- Çocuk yayınlarına yönelik paydaşlar bir araya gelerek "çocuklar için yayın kriterleri" oluşturulması ve baskısı yapılan yayınların bu kriterlere uygunluğunu denetleyen aktif bir komisyon kurulması ilgili kurum/kuruluşlarca sağlanmalıdır.

\section{Kaynakça}

Akyol, H. (2006). Yeni Programa Uygun Türkçe Öğretim Yöntemleri. Ankara: Kök Yayıncılık.

Arslan, C., \& Ceviz, D. (2007). Ev Hanımı ve Çalışan Kadınların Obezite Prevalansı ve Sağlıklı Yaşam Biçimi Davranışlarının Değerlendirilmesi. Fırat Üniversitesi, Să̆llk Bilimleri Enstitüsü Dergisi, 21(5), 211-220.

Ataseven, F., \& İnand1, Y. (2000). Çocuk Kitaplarının Çeşitli Yönleriyle Incelenmesi. 1.Ulusal Çocuk Kitapları Sempozyumu, (Sorunlar ve Çözüm Yolları), Ankara: Ankara Üniversitesi Eğitim Bilimleri Fakültesi ve Tömer Dil Merkezi Yayınları.

Bulut P., \& Kuşdemir Y. (2013). Tübitak Tarafindan Yayınlanan Çocuk Kitaplarının İçerik Özelliklerinin İncelenmesi. Turkish Studies, 8(12), 215-226.

Costanzo, C., Walker, S.N., Yates, B.C., McCabe, B., \& Berg, K. (2006). Physical Activity Counselling For Older Women. West J Nurs Res Suppl, 28(7), 786-801.

Dağlığlu, E., \& Çakmak, Ö. (2009). Okul Öncesi Çocuklarına Yönelik Yayınlanan Hikâye Kitaplarının Şiddet Ve Korku Öğeleri Açısından İncelenmesi. Türk Kütüphaneciliği, 23(3), 510-534.

Edelman, C., and Mandle, C.L. (1986). Health Promotion Throughout the Lifespan, Toronto: The C.V. Mosby Company, , Princeton.

Erkan, N. (1998).Yaşam Boyu Spor. Ankara: Bağırgan Yayınevi.

Filiz, K. (2002). Sporun Tanımlanması ve Kapsamının Belirlenmesi Üzerine Bir Çalışma, Gazi Üniversitesi, Gazi Eğitim Fakültesi Dergisi, 22 (2), 203-211.

Gönen, M., Katrancı, M., Uygun, M., \& Uçuş, Ş. (2011). İlköğretim Birinci Kademe Öğrencilerine Yönelik Çocuk Kitaplarının, İçerik, Resimleme ve Fiziksel Özellikleri Açısından İncelenmesi. Eğitim ve Bilim, 36(160), 250265.

Kuran, Ş. B. (2011). Çocuk Edebiyatı ve Kültür Eğitimi İlişkisi. 3.Ulusal Çocuk Ve Gençlik Edebiyatı Sempozyumu Kitabı (05- 07 Ekim 2011), Ankara: Ankara Üniversitesi Çocuk ve Gençlik Edebiyatı Uygulama ve Araştırma Merkezi. 
Lees, S.J., \& Booth, F.W. (2005). Physical in Activity is a Disease. World Rev Nutr Diet, 95, 73-79.

Öztürk, E., \& Can, I. (2013). İlköğretim 5. Sınıf Öğrencilerinin Elektronik Kitap Okumaya İlişkin Görüşleri. Türkiye Sosyal Araştırmalar Dergisi, 171 (171), 137-153.

Özvarış B. Ş. (2006). Sağlık Ĕgitimi ve Sağllğg Geliştirme, Halk Sağlığ Temel Bilgiler Içcinde (Editörler: Ç. Güler ve L. Akın). Ankara: Hacettepe Üniversitesi Yayınları, Ankara.

Pender, N.J. (1987). Health Promotion in Nursing Practice. California: Norwalk CT.

Redland, A.R., and Stuifbergen, A.K. (1993). Stategies for Maintenance of Health-Promoting Behaviour. Nurs Clin North Am Suppl Jun, 28(2), 427-441.

Sever, S. (2002). Çocuk Kitaplarına Yansıtılan Şiddet (Milli Eğitim Temel Yasası ve Çocuk Haklarına Dair Sözleşme Bağlamında Bir Değerlendirme). Ankara Üniversitesi Eğitim Bilimleri Fakültesi Dergisi, 35(1-2), 26-37.
Tekin, H. (2005). Çocuk Edebiyatında Şiddet Korku ve Sevgi Üçgeni. Hece Edebiyat Dergisi, (104-105), 304306.

World Health Organization/WHO. (2006). Mental Health. (Erişim:

20.12.2019), www.who.int/topics/mental_health/en/

Yıldırım, A., \& Şimşek, N. (2005). Sosyal Bilimlerde Nitel Araştırma Yöntemleri. Ankara: Seçkin Yayıncılık.

Zaybak, A., \& Fadıloğlu, Ç. (2004). Üniversite Öğrencilerinin Sağlığı Geliştirme Davranışı ve $\mathrm{Bu}$ Davranışı Etkileyen Etmenlerin Belirlenmesi. Ege Üniversitesi, Hemşirelik Yüksek Okulu Dergisi, 20(1), 77-95.

Zivtci, F. (2006) Çocuk Kitaplarında Kahramanın Yeri ve Önemi. Ankara: 2. Ulusal Çocuk ve Gençlik Edebiyatı Sempozyumu (04-06 Ekim 2006).

Zorba, E. (2012). Herkes Iç̧in Yaşam Boyu Spor. Ankara: Herkes İçin Spor Federasyonu Yayınları, Neyir Matbaacilık. 


\section{Extended Abstract}

Education is the most common path to take step on for social progress and development. Aim of education is to train a child's consciousness, body and senses. Basis of education is reading. Reading is a process within mental themes. Comprehending what is read is the most substantial aim of reading. An individual who has efficient reading habits is able to get various meanings from what they read, as books are the education materials used frequently to improve reading skills.

Children's books are among the most substantial parts of education. Books, an essential part of education, have an important role on gaining healthy life and sports habits. Children have an opportunity to internalize the characters and their positive behaviors in the story books. Children might interiorize some habits by imitating the characters' behaviors with the help of the books.

Willingness to healthy life and doing sports are the issues that each individual gives importance and aims to keep on. It is only possible to make it conscious by starting at an early age and endearing it. It is essential to make sport habits and healthy life gained by children. It is a must to give these topics a place in children's story books. In the study conducted within this context, it was aimed to determine the frequency of activities about sports and healthy life in passages of the children's story books.

In this study, the survey model was used. This model aims to realize an existing situation as it is. Within this context, it was aimed to evaluate the passages that include sports theme and healthy life in the children's story books.

100 books, which were included in the Public Town Library

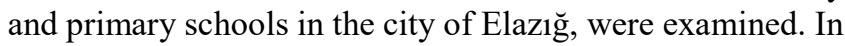
the books that were under investigation, it was observed that activities, such as regular diet, environmental cleaning, regular sleep, teeth hygiene-brushing, diet, the importance of exercise, resting, were included the most as themes of a healthy life. $89 \%$ of these story books were penned by national authors while $11 \%$ of them were penned by foreigner authors.

In the research context, searching the passages of 100 published story books in the publishing houses selected in a random way in terms of healthy life and sports was fulfilled by the researchers with an evaluation form. In the study, in order to have the books analyzed in terms of healthy life and sports themes, primary and secondary resources were aimed to be received. In the study, it was found out that healthy life and sports themes in the story books were not in a formal standard.

As a result of searching about 100 story books, these results were obtained: In the analyzed books, it was determined that activities like playing games, taking pills, bath habits, having a rest, doing sports, going on a diet, teeth care, sleeping regularity, environmental cleaning, regular diet were observed in the highest level as the theme of healthy life. In the books prepared for the children, activities which are supportive for healthy life were observed in lower rate. These activities which will be included in the story books have importance for the children to get healthy life habits. In the analyzed books, swimming, running, horse riding, football, athletics, trekking, hunting, archery, cycling, fishing, wrestling, canoeing, mountain climbing, body building, camping, skiing, dancing, watrer polo, basketball were observed as the theme of sports. It was stated in the books in which the activities that will be taken as sports activities that variety was more. Passages which tell about sports activities were placed in low rate in the books. Consequently, in the children's story books, a small place was given to swimming, horse riding, football, running acitivies as the theme of sports. It was stated that a big place was given to activities like body and environmental cleaning, regular diet, and walking in the passages as the theme of healthy life. These might be presented according to the results received from the study:

- It is essential to convey the habits of healthy life and sports in children's story books, and these subjects must be presented to the parents and in media, as well.

- The passages in the children's story books must be enriched in terms of healthy life activities and sports branches.

- It must be provided that children's story books have more places in the bookshelves of the schools and classrooms.

- Publishing Criterias for Children must be constituted, and a committee must be created to control the suitability of these publishings to those criterias. 